\section{FRI0096 THE ASSOCIATION BETWEEN MIGRAINE AND ANTIPHOSPHOLIPIDE ANTIBODY IN SYSTEMIC LUPUS ERYTHEMATOSUS}

S Appenzeller, LT Costallat, IB Coimbra, MB Bertolo, A Samara. Internal MedicineRheumatology Unit, State University of Campinas, Campinas, Brazil

\subsection{6/annrheumdis-2001.131}

Background Various neurological manifestations have been considered to be important features of Systemic Lupus Erythematosus (SLE) and indicative of Central Nervous System (CNS) involvement. Few studies of SNC include headache and the real prevalence of headache in SLE remain unknown, but some authors consider it one of the most frequent neurological symptoms, especially during acute disease.

Objectives To determine the point prevalence and the different types of headache in patients with SLE. To investigate associations between headache and clinical and laboratory manifestation of SLE, corticosteroid therapy, disease activity and CNS involvement.

Methods A cross-sectional study of 40 patients with SLE was compared to 40 patients with rheumatoid arthritis (RA) and 40 controls. To assess the different types of headache an especial questionnaire was elaborated, according with ACR case definition. Systemic disease activity was measured by SLEDAI. Statistics were performed by chi-square test and by Fisher's exact test. Results Headache was observed in $62.5 \%$ in SLE compared to $47.5 \%(\mathrm{p}=0.26)$ in $\mathrm{RA}$ and to $35.1 \%$ in controls $(\mathrm{p}=$ 0.0247). The types of headaches observed in SLE was migraine in $46 \%$, tension headache in $36 \%$ and $20 \%$ had headaches during their menses. In RA we observed that $15.7 \%(\mathrm{p}=0.05)$ had migraine, $21 \%$ had tension headache, $37.5 \%$ had headache related to visual problems and $26 \%$ had headaches during the menses. In the control people group the prevalence of migraine was $23 \%(\mathrm{p}=0.05)$, tension headache $38 \%$ and headache during the in $38 \%$. There was no significant association between headache and clinical manifestations of SLE, with laboratory abnormalities or the use of corticotherapy. A significant association in SLE was observed between seizures and migraine $(p<$ 0.001 ) and between headache and disease activity $(\mathrm{p}<0.001)$.

When comparing the presence of migraine to clinical and laboratorial results we observe a significant association with Raynauds phenomenon ( $p<0.05)$, LE cels $(\mathrm{p}<0.05)$, antifosfolypid antibodies $(\mathrm{p}<0.001)$.

Conclusion Migraine was more prevalent in SLE than in the control groups. The positive association between migraine and seizures and a higher score at SLEDAI could be related to a greater CNS involvement in these patients. In our study, migraine was associated to antiphospholipid antibodies.

\section{REFERENCES}

1 Omdal R, Mellgren SI, Husby G. Clinical neuropsychiatric and neuromuscular manifestations in systemic lupus erythematosus. Scand J Rheumatol. 1988;17:113-17

2 Adelman DC, Saltiel E, Klinenberg JR. The neuropsychiatric manifestations of systemic lupus erythematosus: an overview. Semin Arthritis Rheum. 1986;15(3):18599

\section{FRI0097 DIAGNOSIS OF NEUROPSYCHIATRIC SLE AND OTHER COLLAGEN-VASCULAR DISEASES USING INFRA-RED OCULOGRAPHY}

${ }^{1}$ DA Maclachlan, ${ }^{2} \mathrm{U}$ Gschwandtner, ${ }^{3} \mathrm{~A}$ Steck. ${ }^{1}$ Department of Rheumatology; ${ }^{2}$ Department of Psychiatry; ${ }^{3}$ Department of Neurology, University Hospital Basel, Basel, Switzerland
Background Minor cognitive deficits such as impaired intellectual performance, poor concentration and mental fatigue are common in patients with SLE and other autoimmune diseases. ${ }^{1}$ There is however no single reliable method for the detection of CNS involvement from autoimmune diseases.

Objectives A non-invasive, highly-sensitive testing method, infrared oculography ${ }^{2}$ was used to investigate whether eye movements are affected in patients with suspected CNS involvement from various autoimmune diseases compared to a normal healthy control group.

Methods 10 patients (5 with SLE, 5 with other autoimmune diseases) with cognitive deficits and 10 control subjects were examined using infra-red oculography to measure disturbances of eye movements and to assess the usefulness in the evaluation of these patients.

Results There were no statistically significant differences between patients and controls when comparing amplitude, latency, duration and velocity of saccadic eye movements (SEM) but there was a significantly higher $(p<0.05)$ number of undershoots with corrective saccades in both groups of patients. In smooth pursuit eye movements (SPEM), there was no significant difference in the gain and delay between the patients and controls but a significantly higher number of correction saccades in patients $(\mathrm{p}<0.01)$ could be shown.

Conclusion We conclude that the measurement of SEM and SPEM is a simple and non-invasive method for identifying suspected neuropsychiatric central nervous system involvement in patients with autoimmune disease.

\section{REFERENCES}

1 Carbotte RM, Denburg SD, Denburg JA. Cognitive deficit associated with rheumatic diseases: neuropsychiatric perspectives. Arthritis Rheum. 1995;38:1363-74

2 Meienberg 0 . Infrared reflection method for recording horizontal eye movements. An improved version for routine diagnostic studies. Fortschr Neurol Psychiatr. 1987;55(5):158-63

\section{FRI0098 THE INCIDENCE AND CLINICAL CHARACTERISTICS OF MYCOBACTERIUM TUBERCULOSIS INFECTION AMONG SLE AND RA PATIENTS IN KOREA}

T Kim, J Yun, D Yoo, J Jun, S Jung, I Lee, S Bae, S Kim. Rheumatology, The Hospital for Rheumatic Diseases, Seoul, Korea

\subsection{6/annrheumdis-2001.133}

Background A prevalence rate in a general population estimated by chest x-ray was reported $1.03 \%$ in 1995 .

Objectives The aim of this study was to describe the incidence and clinical characteristics of $\mathrm{M}$. tuberculosis infection among SLE and RA patients in Korea.

Methods We assessed retrospectively 283 SLE and 284 RA patients with median disease duration of 6 years and 9 years, respectively.

Results Tuberculosis was documented from 15 SLE and 7 RA patients with the incidence rate of 7.9/1,000 patient-years and $2.3 / 1,000$ patient-years, respectively $(\mathrm{p}<0.05)$. SLE-associated tuberculosis included 3 miliary tuberculosis, 7 pulmonary tuberculosis (including 1 diffuse pulmonary involvement with meningitis) predominantly involved in mid-/lower lung field more than 2 lobes, and 5 extra-pulmonary forms (2 osteomyelitis, renal tuberculosis, laryngeal tuberculosis, pleurisy). Four out of seven pulmonary tuberculosis were relapsed cases even after adequately treated. All RA-associated tuberculosis were a pulmonary tuberculosis and most of them were localised to one lobe, and also only 1 case was relapsed. All patients were successfully treated 
except for two died of miliary tuberculosis. A history of high dose steroid or cytotoxic drugs and any organ involvement were not related to the development of tuberculosis. SLE-associated tuberculosis was developed $48.13 \phi^{\circledR . *}$ ú35.14 months after their initial symptom and $20.87 \notin^{\circledR * *}$ ú23.53 months after clinical diagnosis.

Conclusion Taken together characteristics of tuberculosis in SLE patients are; 1) a higher incidence rate, 2) more frequent extrapulmonary involvements, 3) more extensive pulmonary involvements 4) a higher relapse rate (Odds ratio 4.14). Thus, the contributory role of $\mathrm{M}$. tuberculosis infection in the morbidity and mortality of patients with SLE must be emphasised, especially in areas endemic for $\mathrm{M}$. tuberculosis.

\section{REFERENCES}

1 Segal BH, Sneller MC. Infectious complications of immunosuppressive therapy in patients with rheumatic diseases. Rheum Dis Clin North Am. 1997;23:219-37

2 Petri M. Infection in systemic lupus erythematosus. Rheum Dis Clin North Am. 1998;24:423-56

3 Victorio-Navarra STG, Dy EER, Arroyo CG, Torralba TP. Tuberculosis among Filipino patients with systemic lupus erythematosus. Semin Arthritis Rheum. 1996;26:628-34

4 Kim HA, Yoo CD, Baek HJ, et al. Mycobacterium tuberculosis infection in a corticosteroid-treated rheumatic disease paient population. Clin Exp Rheumatol. 1998:16:9-13

5 Kim SJ, Hong YP, Lew WJ, Yang SC, Lee EG. Incidence of pulmonary tuberculosis in Korean civil servants. Tuber Lung Dis. 1995;76:534-9

\section{FRI0099 CAUSES OF DEATH IN 56 PATIENTS WITH SYSTEMIC LUPUS ERYTHEMATOSUS}

EK Li, LS Tam. Department of Medicine \& Therapeutics, Prince of Wales Hospital, New Territories, Hong Kong

\subsection{6/annrheumdis-2001.134}

\section{Background}

Objectives To describe the causes of death in a Chinese lupus cohort with SLE.

Methods We examined mortality in a cohort of 427 Chinese patients with SLE seen between 1985-1997. During a mean \pm SD of $5.0 \pm 3.8$ years of follow-up, 56 patients died. The causes of death were determined.

Results The mean \pm SD disease duration from diagnosis to last visit or death for the 427 patients was $6.7 \pm 5.4$ years, with a duration of follow-up of $5.0 \pm 3.8$ years. 53 females and 3 males died. The age at death was $35.3 \pm 11.3$ years. Among those who died, the duration of disease was $5.2 \pm 4.8$ years with a follow-up of $3.5 \pm 3.3$ years. In comparison, patients last seen alive had a longer disease duration of $6.9 \pm 5.4$ years and a longer follow-up of $5.3 \pm 3.9$ years. Infection and active SLE were the two leading causes of death, occurring in 17 patients (31\%) in both instances. The clinical manifestations amongst the 17 patients with active SLE were as follows: seizure in 2, cerebritis in 1 , cardiac tamponade in 2, pneumonitis in 2, pulmonary haemorrhage in 2, pulmonary hypertension in 2, nephritis in 2, vasculitis in 2, pancreatitis in 2 . In 12 patients, SLE was a contributing factor of death. Thus, active SLE was present in over half of the cases ( 28 patients) at the time of deaths. The most common type of infection was pneumonia (41\%) followed by bacteremias $(35.3 \%)$. The most prevalent infections were bacterial infections $(23.5 \%)$, followed by mixed infections (17.6\%), fungal $(17.6 \%)$ and mycobacterium infections $(17.6 \%)$. Out of the 17 patients in whom the primary cause of death was due to infection, 9 had active SLE at the time of death.
Conclusion The majority of patients at the time of death had active SLE. Although the percentage of patients dying from infections and active SLE were the same, active SLE was present in half of those with infections suggesting that active disease remains the most important factor in mortality in SLE.

\section{FRI0100 PREDNISONE (PRED), AZATHIOPRINE (AZA) AND CYCLOSPORIN A (CSA) COMBINATION IS EFFECTIVE FOR MEMBRANOUS LUPUS NEPHRITIS (MNL)}

EK Li, LS Tam, CC Szeto, FM Lai, SM Wong, CB Leung, KC Wong, SF Lui. Department of Medicine and Therapeutics, Prince of Wales Hospital, New Territories, Hong Kong

10.1136/annrheumdis-2001.135

\section{Background}

Objectives

Methods 10 consecutive female patients with mean age 35 Ó 10 years and the mean disease duration prior to the onset of the index episode of nephritis was 86 Ó 85 months with pure MLN were treated with prednisolone, AZA and CSA for at least 12 months. CSA was tapered in stable patients by 18-24 months. All patients were followed for 3 years.

Results At 1 year, 4 patients achieved complete response as defined as serum albumin over $35 \mathrm{~g} / \mathrm{L}$, urinary protein less than $0.3 \mathrm{~g} /$ day and serum creatinine less than $30 \%$ above the baseline value and 3 achieved partial response. One patient developed agranulocytosis and alopecia totalis, another patient withdrawn at 6 months because of inefficacy, and one patient had no response at 1 year. For the responders, serum albumin increased from 22.8 Ó 5.1 to 34.4 Ó $2.7 \mathrm{mg} / \mathrm{l}$, accompanied by reduction in urine protein from 5.6 Ó 3.2 to 0.8 Ó $0.8 \mathrm{~g}$ /day, while serum creatinine remained unchanged. Significant increase in serum albumin and sustained reduction in urine protein were noted from 3 months onward. Creatinine clearance showed significant improvement by the end of 1 year. Serum C3 normalised in 3 out of 6 patients, whereas anti - ds DNA antibodies became negative in 5 out of 6 patients. The mean prednisone dose reduced from 26.8 Ó 5.5 to 5.7 Ó $1.9 \mathrm{mg} / \mathrm{day}$, the mean dose of CSA also reduced from 235.7 Ó 24.4 to 132.1 Ó $49.4 \mathrm{mg} /$ day at the end of 1 year.

Side effects included hypertension requiring additional antihypertensives in 4 patients, minor infections in 2 patients and leucopenia in 1 patient. CSA was tapered by the end of second year in 4 patients. At 3 years, 6 patients had sustained response, 2 patients developed renal relapse at 18 and 20 months. One patient reached end stage renal failure at 27 months.

Conclusion Combination therapy using prednisolone, AZA and CSA is well tolerated and is efficacious in the management of MLN, and may prevent relapse in patients after stopping CSA.

\section{FRI0101 ANTIRIBOSOMAL-P PROTEIN ANTIBODIES IN SYSTEMIC LUPUS ERYTHEMATOSUS PATIENTS}

S Päi, R Birkenfeldt. Department of Internal Medicine, University of Tartu, Estonia, Tartu, Estonia

\subsection{6/annrheumdis-2001.136}

Background Autoantibodies to ribosomal-P protein (anti-P antibodies) are predominantly found in sera of patients with systemic lupus erythematosus (SLE) and have been correlated with neuropsychiatric lupus in some but not all studies. ${ }^{1}$ The 